\author{
АНДРЕЙ В. ПОЛОНСКИЙ \\ Белгородский государственный национальный \\ исследовательский университет \\ (D) ORCID http://orcid.org/oooo-0oo2-2678-6203
}

\title{
ИНТОЛЕРАНТНОСТЬ И ЕЕ ВИДЫ В ДИСКУРСЕ СОВРЕМЕННЫХ РОССИЙСКИХ СМИ
}

Ключевой приметой современного мира стала повышенная негативная чувствительность к инокультурному фактору, форсированная дифференциация общества на «своих» и «чужих» и обостренная состязательность в сфере ценностных картин мира. Сегодня актуализируются все те содержательные формы и практики, которые составляют сущность интолерантности. Вместо того чтобы совместными усилиями выявить все возможные точки соприкосновения и общие интересы, вместо того чтобы углубить способность человека и общества к диалогу культур, при котором культуры «не сливаются и не смешиваются, каждая сохраняет свое единство и открытую целостность, но [...] взаимно обогащаются» ${ }^{1}$, сегодня все чаще стали акцентированно настаивать на нормативной исключительности своего культурного опыта и образа жизни, строя своих мыслей и чувств, своей системы знаний и ценностных парадигм, форсированно подчеркивая при этом не только недосягаемую ни для кого другого высоту своего нравственно-эстетического выбора, но и свою нерасположенность к мировоззренческой дискуссии, к обсуждению и согласованию своих идей с теми социальными субъектами, которые опознаются оценивающей культурой в терминах инородности, чуждости, ненормативности и инакомыслия.

1 М.М. Бахтин, Эстетика словесного творчества, Искусство, Москва 1986, c. $353-354$. 
Интолерантность, ее понимание, ее основания, ее виды, формы и способы проявления, находится сегодня в фокусе самого пристального общественного внимания. Ей посвящаются многочисленные монографии и сборники работ, диссертационные исследования. На различных научных и медийных площадках свое мнение об интолерантности высказывают как специалисты, представляющие разные сферы экспертного знания, так и все, кого волнуют культурно-нравственные, социально-политические и стилистико-эстетические аспекты жизни современного человека ${ }^{2}$.

Обостренное внимание к проблематике интолерантности не кажется случайным, поскольку сегодня она выступает в качестве широко востребованной культурной и коммуникативной практики, ключевого нравственного, мировоззренческого и коммуникативного принципа, который определяет доминирующий в обществе тип циркулирующих смыслов, высказываний и текстов.

Осмысление широчайшего проблемного поля интолерантности позволяет определить культурный и коммуникативный статус современного человека, его социальную, личностную и гражданскую состоятельность, особенности его мировоззренческого, нравственного и эстетического выбора, политических и культурных сценариев его жизни, его готовность не только к насыщенному в оценочном отношении жесту, к публичному предъявлению своей позиции, своих взглядов и убеждений, но и к публичной дискуссии, к мировоззренческому диалогу, в процессе которого должно рождаться общее для всех понимание социального блага.

2 С. С. Аверинцев, Когда рука не сожмется в кулак, «Век ХХ и мир» 1990, №7, с. 11-17; С.Д. Бакулина, «Свой» - «чужой» в пространстве толерантного/интолерантного сознания // Реальность. Человек. Культура: универсалии научного знания: Материалы Всероссийской научной конференции. Омск, 2O-21 декабря 2007, Омский государственный педагогический университет, Омск 2007, с. 3-5; С.А. Колосов, Конструирование социальной ненависти в дискурсе: Автореф. дис. ... канд. филол. наук. 10.02.19, Тверь 2004; Толерантность и интолерантность в современном обществе в условиях мирового кризиса-2010, Издательство Санкт-Петербургского университета, Санкт-Петербург 2011; Э.В. Чепкина Проблемы толерантности в средствах массовой информации, Издательство Уральского университета, Екатеринбург 2016; M. Czyżewski, Tolerancja i nietolerancja: pojęcia i postulaty, «Etyka» 2011, №44, s. 58-78; J. Habermas, Intolerance and Discrimination, «International Journal of Constitutional Law» 2003, vol. 1, №1, c. 2-12. 
В данной статье интолерантность рассматривается в аспекте практики тех российских СМИ (как традиционных, так и сетевых), которые жестко выстраивают свою информационно-мировоззренческую политику с учетом артикулированно заявленного в 2012 г. принципа - упрочение культурного самосознания российского общества и его консолидация на основе защиты традиционного социального порядка и системы традиционных культурных ценностей - дома, семьи, религии, родины, отечества, истории рода, патриотизма, обычаев, языка и др.

Рассмотрение интолерантности в формате современных СМИ требует уточнения содержания самого этого понятия, поскольку до сих пор, как представляется, не сложилось его общепринятого определения. Авторы исследования «Измерение толерантности», выполненного в 2002 г. в рамках проекта Фонда Защиты Гласности, охватившего шесть регионов Российской Федерации, по этому поводу, в частности, замечают:

В последнее время проблема толерантности / интолерантности вообще и проявление нетерпимости в СМИ является предметом широкого обсуждения; демократически ориентированная часть общества проявляет такой же интерес к искоренению интолерантности, как и к сохранению важной для нее ценности - свободы слова. В связи с этим возникает основная сложность: как отличить проявление нетерпимости, оскорбляющее какието категории граждан или ущемляющие их права, что недопустимо для демократии, от просто другого мнения?3

Интолерантность (лат. intolerantia «нетерпение») понимается как принцип социального взаимодействия на основе идентификации по параметру «свой - чужой», как принцип производства и распределения культурных ценностей на основе позитивного восприятия своего и нетерпимости к другому, интеллектуального и эмоционального переживания другого в модальности акцентированного неодобрения, неприятия и отторжения. Интолерантность сопровождается жестким отказом от мировоззренческого диалога и ценностно-смыслового обмена.

В каждой культуре, безусловно, складывается своя сфера интолерантного, включающая в себя все то, что не может быть терпимо в соответствии с актуальной практикой жизни, культурными ценностями, нормами и правилами общества и человека,

3 Е. Ю. Кольцова, Е.Е. Таратута, Измерение толерантности // «Журнал социологии и социальной антропологии» 2003, т. VI, №4, с. 113. 
поэтому она всегда имеет и национальную, и групповую, и личностную специфику.

В качестве концептуальной основы интолерантности выступает: (1) неприятие культурных различий в любой сфере жизни и деятельности общества и человека - в социальных практиках и образе мыслей, в сфере ценностей и верований, в механизмах поиска истины и способах развертывания публичного диалога и т.п.; (2) позитивное переживание значимости и превосходства собственной культуры, ее опознавание как нормативной, эталонной, не только выгодно отличающейся своими характеристиками от любой другой культуры, но и испытывающей с ее стороны деструктивное воздействие; (3) интерпретация другого, то есть того, чей образ жизни и мысли, чьи мировоззренческие принципы и культурные практики отличаются от оценивающей культуры, как преодолевающего границу установленной нормативности, повторяемости и сходства и по этой причине не только не заслуживающего акцептирующего внимания, но и вызывающего у представителей оценивающей культуры совокупность негативных переживаний-неодобрение,неприязнь, отторжениеилиагрессию.

Интолерантность всегда связана, с одной стороны, с осознанным отказом оценивающей культуры признать отличия другого в качестве репрезентации альтернативной нормы, совокупности узаконенных другой культурой нравственных и эстетических канонов, или, как сказал Евгений Павлович Прохоров, с отказом «впустить в свой мир другого именно как другого, во всей его 'инаковости' и 'особости', а не какой-то маргинальности» 4 , a c другой - с установкой на сохранение собственной культурной традиции, на обеспечение ее позитивной динамики в условиях усиливающегося внешнего воздействия и, как следствие, с формулированием оценивающей культурой разноформатных ограничений в социальной репрезентации оппонирующих ей образов, смыслов, идей, практик, уклада жизни как тех содержательных форм, которые способны качественно изменить ее ценностно-смысловой порядок.

Отказ от культурного диалога, осознанное отторжение иных взглядов, точек зрения и стиля, отказ от культурного и мировоззренческого компромисса, от внесения любых, мотивированных другой культурой содержательных корректировок в собствен-

4 Е.П. Прохоров, Журналистика и демократия, РИП-холдинг, Москва 2001, c. 119 . 
ный опыт - это те практики, которые позволяют интолерантности выступать в качестве амбивалентного механизма, с одной стороны, оппонирования, то есть аналитико-критического и эмоционального возражения, а с другой - пропонирования, связанного с защитой права культуры на самобытность, своеобразие и уникальность.

Интолерантность как принцип нетерпимого отношения к содержательным формам, выходящим за рамки сформулированной оценивающей культурой нормативности, таким образом, неоднозначна: она имеет и позитивный вектор, связанный с обеспечением устойчивости культуры к внешнему воздействию, с обеспечением культурного суверенитета общества, его культурно-исторической памяти, его духовно-нравственных ценностей, что в современном, поликультурном мире должно являться неотъемлемым правом каждого субъекта, и негативный, представляющий угрозу культуре, когда она, оказавшись в режиме непрерывного монолога, говоря словами Дмитрия Сергеевича Лихачева,

по большей части упрощает сама себя, выдвигает вперед знамена с символами и знаками своей индивидуальности, капсулируется в мифах о “национальном характере”, “национальных идеях”, “национальной предназначенности” и т.д. Потери велики, ибо все это бывает связано [...] с повышенными самооценками, с развитием агрессивности в отношении “других” и в конечном счете внутри себя и против себя 5 .

В каждой культуре и в каждую эпоху складываются своя сфера интолерантного, включающая в свои границы то, что не может быть терпимо в соответствии с актуальной практикой жизни общества, его ценностями, нормами и правилами. Сфера интолерантного (обязательно) включает нарушение тех норм, которые регулируются законом или усиленно поддерживаются культурной традицией, а также несправедливость, отказ от личных убеждений, банкротство личностного иммунитета и т.п. Инакомыслие как форма «политического возражения», по определению Юргена Хабермаса ${ }^{6}$, во многих обществах также оказывает-

5 Д. С. Лихачев, Два типа границ между культурами // Д. С. Лихачев, Очерки по философии художественного творчества, Российская академия наук, Санкт-Петербург 1996, с. 97.

6 Ю. Хабермас, Вовлечение Другого. Очерки политической теории, пер. Ю. С. Медведева, ред. Д. А. Скляднева, Наука, Санкт-Петербург 2001. 
ся в сфере интолерантого, поскольку связана с нежеланием или неготовностью властных структур к оппонирующему диалогу, несогласию и оппозиционному мнению.

Анализ корпуса разножанровых текстов, опубликованных в период с 2012 г. по 2019 г. в таких периодических изданиях, как «Завтра», Культура», «Фома», «Военное обозрение», «Московский комсомолец» и др., дает основание для вывода о том, что в современных российских СМИ принцип интолерантности в производстве и распределении оценочных смыслов оказывается чрезвычайно востребованным: явно выраженную интенцию отторжения другого и снижения его культурного статуса содержит значительная часть всех текстов. Их количество, безусловно, колеблется - и даже весьма значительно - в зависимости от средства массовой информации, текущих обстоятельств общественной и политической жизни в мире и стране. Основным носителем интолерантных смыслов в российских СМИ сегодня является не только традиционно политическая и идейно-мировоззренческая тематика, но и экономическая, культурно-историческая, культурно-развлекательная, спортивная, криминальная, семейно-бытовая и молодежная.

Российское общество, чтобы не оказаться в зоне экономического и духовного риска, чтобы не утратить ориентиры нравственности, продолжает активно обсуждать систему ценностей, которые должны лежать в основе его жизни и деятельности, его задач и перспективных проектов, поэтому вопросы мировоззренческого выбора остаются чрезвычайно актуальными. Не случайно поэтому объектами интолерантности в рассматриваемых СМИ оказываются те социальные теории, политические практики и концепты политической культуры, которые своей повесткой дня угрожают национальной картине мира, которые воспринимаются как фактор политического оппонирования национальной системе ценностей и которые, таким образом, не соответствуют национальным интересам. Среди них - «западные ценности» (как говорится в одной из газет, «от западных ценностей - бегом в Россию»7), «либерализм», «мультикультурализм», «толерантность», «глобализация», «феминизм», «космополитизм», «атеизм».

Ср.:

Сближение с Европой может грозить России навязыванием ей безнравственных установок, касающихся, в том числе, и института семьи... Демон-

7 https://www.bragazeta.ru/news/2015/o8/12/tolerantnost/ (10.02.2019). 
таж ценностной системы, который сегодня происходит в Европейском союзе, он, конечно, не может нас не беспокоить. Потому что хотя наша страна не является членом Европейского союза, она является, безусловно, частью европейского культурного и цивилизационного пространства. И мы должны понимать, что вот эти ценностные установки, которые сегодня навязываются в Европе, конечно, проникают к нам, и они будут проникать - причем любое сближение с Европой будет непременно связано с навязыванием нам вот этих нравственных норм и нравственных установок ${ }^{8}$.

В рассматриваемых российских СМИ, либерализм, к примеру, подается как правило, не как политическая идеология, определяющая права и свободы граждан, акцентирующая внимание на интересах не только общества, но и личности, на законе как основе функционирования общества, а как ложная идея, как высвобождение всего ранее табуированного, высвобождение любой извращённой сущности, как форма болезни.

Cp.:

Либерализм - это болезнь и лечится с большим трудом, как и всякая прочая психопатология («Завтра». 26 августа 2018 г.)

Эта болезнь называется либерализм. [...] До него нельзя подняться, до него можно только упасть. Нравственное падение = либерализм. Поэтому нельзя поддаваться призывам к раскрепощению и «европейским ценностям», ибо это падение («Военное обозрение». 9 апреля 2013 г.) ${ }^{10}$;

Наполняя головы знаниями, делая человека более информированным, развивая его интеллект, либерализм, одновременно внедряет в головы людей свои ложные ценности, ослабляя разум человека [...]. До какой степени надо лишиться разума, при высоком коэффициенте интеллекта, чтобы принимать либеральные ценности за руководство к действию!? («Русская народная линия». 16 августа 2013 г.) $)^{11 ;}$

Либерализм - это всеохватное и тотальное учение, заходящее в атаку на человеческий ум с разных направлений и атакующий личность под разными углами с целью полностью изменить ее сущность (Культура-Воронеж. РУ. 9 октября 2019 г.) $)^{12}$.

Феминизм с момента своего появления в качестве философской концепции, политической идеологии и общественно-политического движения, выступающего не только за ликвидацию всех форм гендерной дискриминации, за гендерное равенство

8 https://foma.ru/sblizhenie-s-evropoj-mozhet-grozit-navyazyivaniem-rossiibeznravstvennosti.html (10.02.2019).

9 http://zavtra.ru/blogs/liberalizm (10.02.2019).

${ }^{10}$ https://topwar.ru/26513-liberalizm-eto-razlozhenie.html (10.02.2019).

${ }^{11}$ https://ruskline.ru/analitika/2013/o8/16/prowaj_bezdetnaya_evropa/ (10.02.2019).

12 https:культура-воронежа.рф/либеральная-религия-модерна/ (10.02.2019). 
в общественных и бытовых правах, обязанностях и возможностях мужчин, женщин и представителей «небинарной гендерной идентичности», но и с артикулированным призывом к защите природы, также оказывается в российских СМИ в фокусе агрессивно-негативной оценочности. СМИ представляют феминизм как движение озлобленных, неуравновешенных, некрасивых, не удовлетворенных жизнью и не очень успешных в социальном и личностном плане женщин:

Костяк радикальных феминисток, безусловно, составляют идейные личности, главная цель которых стереть любые различия, нарушить сами основы бытия. Это жуткая уравниловка по всем параметрам - гендерным, сексуальным, социальным и так далее. Бунт против самой природы - бессмысленный и беспощадный, потому что изменить вводные данные невозможно ${ }^{13}$.

Социальная реальность, конструируемая российскими СМИ, представлена значительным количеством переживаемых в модальности акцентированного отторжения образов «чужого», образов носителей той или иной культуры и системы ценностей. Среди них выделяются европейцы (граждане Евросоюза), американцы, украинцы, поляки, жители прибалтийских стран, представители раскольнической Православной цјеркви Украины (ПЦУ). Вырисовывается их обобщенный образ: все они - независимо от их практики жизни и мировоззренческого выбора - безнравственны, ориентированы только на свои потребности и интересы, заняты решением только своих задач и при этом чрезвычайно опасны, поскольку в своей эйфорической очарованности открытостью, толерантностью, политкорректностью или правом на самоопределение препятствуют, по мнению СМИ, российскому обществу в его духовном продвижении, в формировании большого «русского мира»:

Интолерантное отношение, обнаруживаемое в российских СМИ к каждой их этих групп, безусловно, имеет свою, дополнительную мотивацию, в случае европейцев, например, она связана с широчайшей проблематикой беженцев, «новых граждан Евросоюза», на языке которых заговорили сегодня не только уличные и дорожные указатели, не только национальные СМИ, но и переписанная вязью Конституция Германии.

${ }_{13}$ https://www.mk.ru/social/2019/02/10/sekta-radikalnogo-feminizma-pochemumodnaya-ideologiya-stanovitsya-izvrashheniem.html (10.02.2019). 
Cp.:

«Кто в этом доме теперь хозяин» - лучше спросить у тех немцев, которых выгоняют из своих квартир на улицу» (5 канал Российского ТВ. Программа «Известия. Главное». 26 октября - 1 ноября 2015 г. $)^{14}$.

В качестве посторонних, не совпадающих по ценностям, взглядам, культурным практикам, в российских СМИ выступают представители некоторых социальных групп, среди них прежде всего - либералы, граждане мира, ЛГБТ-сообщество и т.п. В СМИ они представляются как люди, чуждые сознанию современного россиянина, как те, кто перешел границу сформулированной обществом культурной нормы, и как те, кто своим выбором и социальным жестом, создает потенциал деградации, падения и разрушения: «..все извращенцы всегда, удивительным образом, либералы. Потому и называются либерасты...» («Военное обозрение». 9 апреля 2013 г.) $)^{15}$.

В российских СМИ в сфере усиленного осуждения оказываются и некоторые гендерные аспекты жизни современного человека - мужчины и женщины, которые сегодня стремятся всячески реализовать и закрепить свое право на равенство, на выбор, на независимость и “биархат”, то есть эгалитарную семью, в которой муж и жена равноправны. Однако патриархальный ренессанс, утверждение традиционной гендерной нормативности и гендерной асимметрии, о чем все активнее сегодня заявляется в публичных дискуссиях и что наблюдается практически во всех сферах жизни современного россиянина, оказывает влияние на увеличение в СМИ количества высказываний, в которых крайне негативно оценивается изменение традиционного стандарта гендерно-ролевой идентичности, любая, нарушающая принятую традицию динамика гендерно дифференцированных моделей поведения.

Cp.:

Женщина, отказывающаяся от своей природы, идущая против природы, уже не может называть себя женщиной - это просто женоподобное нечто (Русская народная линия. 16 августа 2013 г.) ${ }^{16}$.

Среди объектов интолерантности, вокруг которых в российских СМИ сегодня создается особое, насыщенное негативной оценочностью смысловое пространство, находятся разные персоны, опознаваемые как политические противники или оппоненты.

${ }^{14} \mathrm{https}: / /$ www.5-tv.ru/glavnoe/broadcasts/508880/244/ (10.02.2019).

${ }^{15} \mathrm{https} / / /$ topwar.ru/26513-liberalizm-eto-razlozhenie.html (10.02.2019).

${ }^{16} \mathrm{https} / / /$ ruskline.ru/analitika/2013/o8/16/prowaj_bezdetnaya_evropa/ (10.02.2019). 
Одну из групп составляют лидеры тех государств, с которыми не складывается политический диалог и которые выступают в процессе политического взаимодействия как субъекты, представляющие в дихотомии «друг - враг», предложенную Карлом Шмиттом («Специфическое политическое различение, к которому можно свести политические действия и мотивы, - это различение друга и врага» $\left.{ }^{17}\right)$, сферу конфликта и соперничества. Среди них - Дональд Трамп, Тереза Мей, Эммануэль Макрон, Петр Порошенко, Владимир Зеленский.

Cp.:

Если раньше хорошо подвешенный язык мог довести только до Киева, то в современной Украине он катапультировал своего обладателя Владимира Зеленского на расстояние вытянутой руки от киевского президентского трона... Зеленский, человек с кашей в голове, явно не понимающий разницы между «реальностью» его киношных сериалов и той реальностью, которая есть на самом деле ${ }^{18}$.

Вторая группа формируется из тех персон, которые в условиях текущего политического контекста опознаются как политические диссиденты, как «политические предатели», выступающие против принятой обществом и властью повестки дня. В «Иудово племя», «ментальной родиной», которого является Запад, как говорят некоторые российские СМИ об этой группе персон, входят Михаил Горбачев, Борис Ельцин, Андрей Макаревич, Лия Ахеджакова, Ксения Собчак и некоторые другие.

Интолерантиность как принцип жесткого отторжения опыта иной культуры, таким образом, широко представлена в российских средствах массовой информации. В зависимости от избранного объекта интолерантности можно выделить ее виды, среди которых самыми репрезентативными являются политико-идеологическая, культурно-гендерная и личностно-мировоззренческая.

Политико-идеологическая интолерантность в СМИ своим объектом определяет системы политических ценностей, социально-политических взглядов, теории, идеи и идеалы, которые обусловливают особенности политического сознания граждан и модели их политической активности.

${ }_{17}$ К. Шмитт, Понятие политического, пер. А. Филиппов // «Вопросы социологии» 1992, №1, с. 40.

${ }^{18}$ https://www.mk.ru/politics/2019/04/o1/chem-opasen-zelenskiy-na-postu-prezidenta-ukrainy.html (01.04.2019). 
Культурно-гендерная интолерантность проявляется в анализируемых российских СМИ в аспекте прежде всего динамики гендерной идентичности, идентификации себя в культурно-ролевом статусе мужчины, женщины или «третьего пола», своеобразно сочетающего мужские и женские признаки.

В сфере личностно-мировоззренческой интолерантности в СМИ находятся убеждения участников политической коммуникации, их симпатии и антипатии, их отношение к нормам и традициям социальной действительности, политическим решениям и практикам. Личностно-мировоззренческая интолерантность связана с неприятием личностно обусловленного характера «прочтения» тех или иных событий в мире и стране. Она включает в себя неприятие духовного и культурного формата личности, неприятие тех переживаний и выводов, в которых отражаются оппозиционные к оценивающей культуре ценностные смыслы. Личностно-мировоззренческая интолерантность затрагивает, безусловно, разные социальные группы, не только представителей определенных политико-идеологических концепций или движений, но и людей, чьи увлечения, интересы или модели поведения воспринимаются как необычные.

СМИ - важнейшая мотивирующая сила общества, ключевая составляющая часть его публичного коммуникативного пространства. От качества разворачиваемого в средствах массовой информации общественного диалога и его духовно-нравственной высоты зависит характер жизни человека. Интолерантность как принцип смыслового производства в современных СМИ имеет несомненную исследовательскую перспективу, поскольку именно в СМИ сегодня концентрированно локализуются практики неприятия и отторжения другого, неуважительного к нему отношения, неодобрения его мировоззренческого выбора. Именно СМИ сегодня форсированно транслируют в общество формулы чуждости, ксенофобии и агрессии по отношению к тем или иным этносам, социальным группам, сообществам, персонам и формам их культуры. Именно в СМИ сегодня активно разрабатываются механизмы снижения культурного статуса другого, лишающие и общество, и человека возможности свободно использовать весь свой когнитивный, нравственный и политический потенциал. 


\section{БИБЛИОГРАФИЯ}

Averintsev, Sergey. "Kogda ruka ne sozhmetsya v kulak." Vek XX i mir 1990, no. 7, s. 11-17 [Аверинцев, Сергей. “Когда рука не сожмется в кулак.” Век XX и мир 1990, №7, c. 11-17].

Bakhtin, Mikhail M. Estetika slovesnogo tvorchestva. Moskva: Iskusstvo, 1986 [Бахтин, Михаил М. Эстетика словесного творчества. Москва: Искусство, 1986].

Bakulina, Svetlana D. “'Svoy' - 'chuzhoy’v prostranstve tolerantnogo/intolerantnogo soznaniya." Real'nost'. Chelovek. Kul'tura: universalii nauchnogo znaniya: Materialy Vserossiyskoy nauchnoy konferentsii. Omsk, 20-21 dekabrya 2007, Omsk: Izd-vo OmGPU, 2007, s. 3-5 [Бакулина, Светлана Д. “'Свой' - 'чужой' в пространстве толерантного/интолерантного сознания.” Реальность. Человек. Культура: универсалии научного знания: Материалы Всероссийской научной конференции. Омск, 20-21 декабря 20о7, Омск: Izdvo OmGPU, 2007, c. 3-5].

Chepkina, Elina V. Problemy tolerantnosti $v$ sredstvakh massovoy informatsii. Yekaterinburg: Izdatel'stvo Ural'skogo universiteta, 2016 [Чепкина, Элина. Проблемы толерантности в средствах массовой информации, Екатеринбург: Издательство Уральского университета, 2016].

Czyżewski, Marek. "Tolerancja i nietolerancja: pojęcia i postulaty.” Etyka 2011, no. 44 , s. 58-78.

Habermas, Jurgen. "Intolerance and Discrimination." International Journal of Constitutional Law 2003, vol. 1. 2-12.

Habermas, Jurgen. Vovlecheniye Drugogo. Ocherki politicheskoy teorii. Per. s nem. Sankt-Peterburg: Nauka, 2001 [Хабермас, Юрген. Вовлечение Другого. Очерки политической теории. Пер. с нем. Санкт-Петербург: Наука, 2001]

Kolosov, Sergey A. Konstruirovaniye sotsial'noy nenavisti $v$ diskurse. Avtoref. dis. ... kand. filol. nauk. 10.02.19, Tver', 2004 [Колосов, Сергей А. Конструирование социальной ненависти в дискурсе. Автореф. дис. канд. филол. наук. 10.02.19. Тверь, 2004]

Kol'tsova, Yekaterina. Taratuta, Yekaterina. "Izmereniye tolerantnosti." Zhurnal sotsiologii $i$ sotsial'noy antropologii 2003, t. VI, no. 4, s. 113 [Кольцова, Екатерина. Таратута, Екатерина. “Измерение толерантности.” Журнал социологии и социальной антропологии, 2003, т. VI, №4, с. 113].

Likhachev, Dmitriy. "Dva tipa granits mezhdu kul'turami.” Likhachev, Dmitriy. Ocherki po filosofii khudozhestvennogo tvorchestva, Sankt-Peterburg: Blic, 1996. 97-102 [Лихачев, Дмитрий С. “Два типа границ между культурами.” Лихачев, Дмитрий С. Очерки по философии художественного творчества, Санкт-Петербург: Блиц, 1996. 97-102].

Prokhorov, Yevgeniy P. Zhurnalistika i demokratiya. Moskva: RIP-kholding, 2001 [Прохоров, Евгений П. Журналистика и демократия, Москва: РИПхолдинг, 2001]

Schmitt, Karl. Ponyatiye politicheskogo. Per. Filippow, Alexandr. Voprosy sotsiologii 1992, no. 1. 37-67 [Шмитт, Карл. Понятие политического. Пер. Филиппов, Александр. Вопросы социологии 1992, №1. 37-67.

Tolerantnost' i intolerantnost' $v$ sovremennom obshchestve $v$ usloviyakh mirovogo krizisa-201o. Sankt-Peterburg Izdatel'stvo Sankt-Peterburgskogo universiteta, 2011 [Толерантность и интолерантность в современном обществе в ус- 
ловиях мирового кризиса-2010, Санкт-Петербург: Издательство СанктПетербургского университета, 2011].

Andriej Połonskij

NIETOLERANCJA I JEJ PRZEJAWY

W DYSKURSIE WSPÓŁCZESNYCH MEDIÓW ROSYJSKICH

Streszczenie

$\mathrm{W}$ artykule rozpatrywany jest problem nietolerancji jako wyjątkowo aktualny we współczesnym świecie w odniesieniu do normy kulturowej i komunikacyjnej jako kluczowej zasady moralnej, światopoglądowej, komunikacyjnej, która określa dominujący w społeczeństwie typ zmiennych sensów, wartościowań w wypowiedziach i tekstach. Autor przedstawia przejawy nietolerancji we współczesnych mediach rosyjskich.

\section{Andrey Polonskyi}

\section{INTOLERANCE AND ITS TYPES \\ IN THE DISCOURSE OF MODERN RUSSIAN MASS MEDIA}

Summary

The article deals with intolerance as a widely used cultural and communicative norm, as a key moral, ideological and communicative principle, which determines the dominant type of circulating messages, statements and texts in society. The author considers its separate types in modern Russian mass media. 